\title{
Kant e a resposta à pergunta: vivemos agora em uma época esclarecida?
}

\section{Kant and the answer to the question: do we live in an enlightened age?}

\section{Wagner Barbosa de Barros}

Graduado, Curso de Bacharelado em Filosofia, Universidade Federal de São Carlos - UFSCar, São Carlos, SP Brasil

Resumo: Tendo em vista a afirmação kantiana de que o esclarecimento (Aufklärung) é a saída do homem de sua menoridade da qual ele próprio é culpado, objetivamos, no presente texto, desenvolver os meios pelos quais é possível a passagem da menoridade para a maioridade e, posteriormente, quais as relações que Kant estabelece entre sua compreensão de esclarecimento (Aufklärung) e a importância do papel que o uso público da razão desempenha em sua filosofia.

Palavras-chave: Aufklärung; história; Kant; maioridade.

Abstract: In view of the kantian affirmation that the enlightenment (Aufklärung) is the man's emergence of his minority, which he himself is guilty, we intend, in the present text, to develop the means by which it is possible the passage from minority to majority and, afterward, which are the relations that Kant estabilishs between his understanding about enlightenment (Aufklärung) and the importance that the public use of reason plays in his philosophy.

Keywords: Aufklärung; history; Kant; majority. 


\section{1) O que é Aufklärung?}

A ideia de esclarecimento (Aufklärung) pode ser compreendida na medida em que desenvolvemos o pensamento kantiano a respeito do conceito de liberdade presente em seu ensaio, ou seja, ao apontarmos a tendência dos homens ao pensamento livre, poderemos apreender as razões pelas quais Kant afirma a necessidade da passagem da menoridade à maioridade racional. Conforme a brevidade de nossa tarefa, temos o objetivo então de, ao analisarmos os principais conceitos kantianos presentes no texto, realizarmos um exame sobre a relação estabelecida entre a ideia kantiana de Aufklärung e a importância do pensamento autônomo por meio do uso público da razão.

A ideia central, segundo Kant, da Aufklärung é a passagem da menoridade para a maioridade, ou seja, a relação estabelecida entre o indivíduo ou mesmo um povo e a sua liberdade de pensamento. Sendo assim, a menoridade é, de acordo com Kant (2011, p.63), "a incapacidade de fazer uso de seu entendimento sem a direção de outro indivíduo", visto que os homens já foram libertos de qualquer tendência reflexiva exterior pela natureza, configurando desta maneira, seja qual for a orientação que receber, uma direção estranha ao seu pensamento, que naturalmente é autônomo.

A menoridade é uma culpa direcionada ao próprio indivíduo, pois refere-se à inconformabilidade na qual ele se insere quando se ausenta da autonomia de suas reflexões. Este estado caracteriza-se pelo direcionamento do pensamento por outro indivíduo, em outras palavras, um tutor. Podemos referenciar, assim como Kant (2011, p.64) faz, um livro, um diretor espiritual ou um método que decida sobre os meios pelos quais um homem configura sua vida, como alguns destes tutores que protagonizam a liberdade de pensamento alheia. Eles são causadores da menoridade, pois anulam potencialmente a individualidade racional do menor, sendo assim, $\mathrm{o}$ tutelado prefere buscar as respostas que anseia em um livro, por exemplo, ao invés de por ele mesmo, encontrar meios em seu próprio pensamento para resolver seus impasses. Ao afirmar isso Kant não recrimina a utilização de um livro ou a recomendação de um guia espiritual. O que o filósofo de Königsberg tem em mente é a ausência de entendimento diante destas situações, que é a causa fundamental do estado de menoridade. O homem, então, não pode ser coadjuvante de sua racionalidade. Ora, deve, ele mesmo, desenvolver e sustentar seus pensamentos sem que busque no outro aquilo que pode encontrar em si, fazendo de sua racionalidade o principal meio para a compreensão de sua realidade, sem que precise do outro como apoio de seu raciocinar. A ousadia do pensamento próprio está na tarefa de compreender-se como aquele que é o responsável por essa atitude, estando, assim, desautorizado a ser instrumento racional alheio, pois compreende a inaceitabilidade desta ação.

Assim que compreendemos o que é a menoridade, posicionamo-nos perante as questões referentes aos motivos pelos quais os homens, ainda que essencialmente livres em seus pensamentos, permanecem sob a tutela racional alheia. Para Kant (2011, p.64), estas causas são a "preguiça e a covardia". E quando um homem deixa que outro assuma sua responsabilidade racional, ele ausenta-se dessa atividade, $o$ que nos leva a compreender que lhe é um estado confortável, ao menos enquanto este indivíduo não for cônscio dos resultados de sua menoridade racional. Afirmamos que este estado é agradável, pois o indivíduo que se submete a ele não tem a necessidade de exercer seus esforços racionais para compreender o meio em que está inserido; sua realidade é então examinada por meio de métodos, fórmulas ou preceitos alheios à sua racionalidade.

Podemos dizer por conseguinte, que a passagem para a maioridade não se encerra, por exemplo, em uma mudança de líderes ou com o acontecimento de uma guerra, visto que a subordinação exercida pelos tutores é essencialmente reflexiva, mas sim pela revolução do pensamento, que é o único movimento que pode realizar uma 
mudança efetiva na disposição racional humana. Ora, enquanto mudam-se os líderes, não necessariamente se transforma o pensamento de um povo, pois a opressão reflexiva pode continuar a ser exercida, e é provável que seja, visto os benefícios que um líder pode tirar da menoridade alheia.

A Aufklärung então, assim como a conformidade do termo alemão sugere, é uma ação que se configura pela saída (Ausgang) da menoridade para a maioridade, e não como algo estático que foi alcançado por um povo ou por alguém. A ideia kantiana de esclarecimento (Aufklärung) requer a compreensão do esforço humano em realizar a árdua passagem entre o desvencilhar-se dos grilhões externamente exposto e o alcance da autonomia racional, que é digna de seu gênero. Podemos compreender, assim, que a passagem à maioridade não é um processo fácil de acontecer, visto que o gérmen que propicia esta sucessão é frequentemente repelido pelos tutores, que querem continuamente tirar proveitos da inferioridade racional alheia. Eles mistificarão, desta forma, toda a possibilidade da transposição entre ambos os estados racionais, caracterizando a ausência de qualquer guia racional como perigosa e ameaçadora para a própria humanidade. Tendo em mente que quem se submete a estas crenças são homens que racionalmente não têm autonomia para refletir sobre elas, acatam, então, facilmente, os dizeres de seus tutores. A maioridade, ou seja, o estado no qual o sujeito frequenta seus próprios pensamentos e vê neles a potencialidade para todas as suas necessidades, só é possível quando se dispõe ao gênero humano a liberdade de pensamento, aquela que Kant caracteriza como uso público da razão. Vejamos, então, como este é composto.

\section{2) O que é uso público e privado da razão?}

Para respondermos a presente questão devemos relembrar o papel que a liberdade exerce no processo do esclarecimento (Aufklärung), porque estamos diante da condição essencial para que ele aconteça, ou seja, o uso público da razão. O filósofo afirma que o uso público da razão é aquele feito por meio de uma discussão relacionada a um tema sob um aspecto mais acadêmico ou literário, com o chamado "público letrado", como a publicação impressa de um tratado, um ensaio ou um artigo. Já o uso privado é aquele que se dirige diretamente ao público de uma associação ou grupo social, escolar ou religioso, em que o próprio indivíduo estabelece a decisão de divulgar e explicitar o que tomou para si como verdade; portanto, alguém que tem uma representatividade em face de um grupo específico utiliza-se dela para exteriorizar aquilo que acredita ser o melhor para determinada questão.

Com base nesta diferenciação e direcionando nossa compreensão às conceitualizações prévias sobre a liberdade e autonomia de pensamento, podemos observar os motivos pelos quais Kant estipula que somente o uso público da razão é aquele que proporciona o esclarecimento (Aufklärung) do gênero humano, uma vez que quando um letrado traz a público um ensaio, por exemplo, sobre um tema, submete-o à avaliação daqueles que o lerão, proporcionando assim, no ambiente erudito, um entusiasmo quanto à sua discussão. Aliberdade do uso público da razão impede que o pensamento e suas ideias sejam submetidos a qualquer repressão possível, o que Menezes (2000, p. 156), no trecho a seguir, traduz eficazmente:

A Aufklärung requer como conditio sine qua non a liberdade, aparentemente a mais inofensiva, ou seja, a de fazer uso público da razão. Ela é inofensiva porque em nenhum momento vem em prejuízo do seu agente. Pelo contrário, ela é sempre meio de esclarecimento, de transparência. Ora, se o exercício da liberdade se faz em público é indispensável a transparência, o outro deve conhecer minhas posições e vice-versa. Determinada máxima que eu não posso tornar pública, levanta contra ela justificativas suspeitas. Por isso, o uso público da razão traz a possibilidade de romper com o ciclo vicioso da menoridade, segundo a qual o tutor impõe ao menos um pensamento pré-estabelecido e sem nenhuma discussão, conserva-o sob a sua guarda espiritual. 
O uso privado da razão é em sua maioria limitado, porque ninguém designado a certo cargo ou função, particular ou pública, poderá estipular questionamentos ou preceitos que contrariem tudo aquilo que deve executar no exercício de suas funções. Neste caso, toda a problemática que for feita em nível público não poderá assim conflitar diretamente com seu cargo, já que dessa maneira estaria em contradição, porquanto opinaria de maneira oposta ao seu atual exercício. Em sua totalidade, qualquer uso privado da razão se submete não somente à perspectiva reflexiva de um determinado debate, mas se mantém subordinada à perspectiva particular de quem faz tal uso, visto que o uso privado da razão recebe exteriormente um direcionamento em suas argumentações, já que elas devem adequar-se ao cargo ou função daquele que exerce tal pensamento. Não poderíamos, por conseguinte, admitir um religioso que pense de uma maneira, mas em seus sermões diga aos fiéis algo contrário.

Tendo isso em mente, podemos compreender as razões pelas quais Kant atribui um caráter esclarecedor limitado ao uso privado da razão, uma vez que não dispõe da eficácia e estímulo reflexivo sobre aqueles que se submetem a tal uso. O uso privado não proporciona o esclarecimento (Aufklärung), porque esta não é essencialmente livre, pois sempre está sob coordenadas exteriores, por exemplo, a de um cargo público. Não poderíamos, então, admitir que alguém que pense, segundo aquilo que lhe é permitido pensar seja propiciador da passagem à maioridade, na medida em que não teria ferramentas eficazes para assegurar tal processo.

Outro caráter que podemos evidenciar quanto à primazia do uso público perante o privado da razão sobre o processo esclarecedor, que cada um propicia ao gênero humano, é a subjetividade imbuída no primeiro uso, o que contrariamente não ocorre no segundo. Ora, no uso público da razão, as opiniões que são expostas no tribunal intelectual são resultados dos germes racionais desenvoltos livremente na própria racionalidade do indivíduo, ausentando-se desta maneira de qualquer empecilho ou direcionamento exterior.

Destarte, podemos afirmar que o início de todo o processo do esclarecimento (Aufklärung) é resultado do impulso gerado na própria subjetividade dos homens. Isto pode ser confirmado quando trazemos à nossa análise a máxima proposta por Kant (2011, p.64) do esclarecimento (Aufklärung): “Sapere aude! Tem coragem de fazer uso de seu próprio entendimento". Isto é, o filósofo alemão não propõe uma transformação no pensamento de um líder ou de um guia, para que então estes possam melhor gerir a vida de seus tutelados, mas, sim, uma mudança no pensamento de cada indivíduo, para que as transformações sejam eficazes. Esta é a interpretação desenvolta por Bicca (1997, p. 23), como podemos ver a seguir:

Pode-se pensar que esclarecimento é antes de tudo auto-emancipação, tarefa que tem de ser enraizada, querida e conduzida por e em cada indivíduo humano. Daí que esclarecimento não pode ser imposto, trazido pronto e acabado por outrem, pois se o que se pretende é um livrar-se de determinados preconceitos disseminados por pretensas autoridades, o simples fornecimento unilateral de "novas verdades" arriscar-se-ia a produzir o oposto do que se deseja, ao se efetivar simplesmente uma substituição de uma crença dogmática por outra.

Um homem pode até adiar o esclarecimento (Aufklärung), mas jamais renunciar a ele; fazer isso seria ir contra os propósitos da humanidade, ou seja, impossibilitaria o avanço do gênero humano e estipularia que o estado alcançado seria o de máxima perfeição a todos; fazer isso seria, ainda, tirar um direito imprescindível da humanidade, o de se tornar cada dia melhor. Assim como um indivíduo não deve decidir por todo o seu gênero, um líder político ou religioso, que no caso representa a vontade geral daqueles que se subordinam a este, não deve estabelecer a seus tutelados uma espécie de censura a determinadas questões; muito menos estabelecer para si próprio uma liberdade irrestrita, da qual poderia surgir um tirano, que acabaria por hostilizar e coibir aqueles à sua volta, para somente aceitarem passivamente suas concepções 
e ordenamentos. Após as imprescindíveis delimitações conceituais e objetivos da presente análise, podemos passar a resposta da pergunta kantiana: se sua época é ou não esclarecida.

\section{3) Vivemos em uma época esclarecida?}

Temos que nos acautelar quando relacionamos uma filosofia à sua época, visto que ela não se encerra num período histórico nem necessariamente é resultado dele. O pensamento filosófico não se exaure quando atribuímos aos fatos históricos a lógica reflexiva, e isto fica ainda mais evidente na presente análise quando compreendemos a composição kantiana de Aufklärung, que não é algo estático, ou seja, que se encerra em uma determinada época, mas sim um incessante processo da passagem do gênero humano da menoridade à maioridade. Sendo assim, ao questionarmo-nos então se a época em que Kant viveu, de acordo com o próprio filósofo, é ou não esclarecida, não tentamos moldar seu pensamento como resultado da situação em que a Prússia se encontrava naquele momento, mas apontar que, por meio da própria caracterização que estipula à sua concepção de Aufklärung, Kant pôde observar em sua contemporaneidade o constante processo de passagem à maioridade acontecer.

O elogio a Frederico II, no ensaio Resposta à pergunta, que é esclarecimento (Aufklärung)?, resulta desta conformação que dispomos acima, ou seja, ainda que a Prússia se encontrasse politicamente desestruturada, com grande atraso econômico e social, seu rei ficou conhecido por oferecer ao povo a possibilidade de pensar o quanto quisesse, desde que obedecesse. Sendo assim, dada a nebulosidade em que o país se encontrava, a permissão para exercer o livre pensar configura-se como um grande avanço no processo do esclarecimento (Aufklärung). Para o filósofo alemão, a atitude de Frederico II é memorável, porque a liberdade de pensamento, essencial para que o processo do esclarecimento (Aufklärung) ocorra, não foi negada ao seu povo, estabelecendo aos seus súditos a autorresponsabilidade pelos seus pensamentos, o que é de extrema importância, visto que Kant estipula um caráter espontâneo da passagem à maioridade. Um rei teria a possibilidade de moldar o pensamento de seus súditos, conforme os poderes que lhe são próprios, porém não é o que Frederico II faz, e é essa mudança de perspectiva que o caracteriza como um déspota esclarecido, uma vez que ainda que tivesse a autoridade para controlar a esfera reflexiva de seu povo, deixa-o livre, ao menos, para pensar o quanto quisesse.

Algo que talvez cause estranheza a quem lê o ensaio kantiano é a possível incompatibilidade que pode, num primeiro momento, ser estabelecida entre o elogio a Frederico II e a liberdade de pensamento, tendo em vista que ele ainda submete seu público às ordens de seu reinado. Ainda mais se refletimos os limites da autonomia racional, na época de Kant, quando temos em mente os dizeres de Frederico II: "raciocinais tanto quanto quiserdes e sobre qualquer coisa que quiserdes; apenas obedecei!".

Novamente é necessário prendermos nossa atenção à própria imagem do esclarecimento (Aufklärung) kantiana como uma mudança que ocorre essencialmente no pensamento. Vimos que, quando se mudam os líderes por uma revolução ou guerra, não obtemos a garantia de que ocorra conjuntamente uma mudança da perspectiva reflexiva do povo. Porém, quando esta desejada mudança ocorre sobre a maneira de refletir acerca do mundo, ela é eficaz e duradoura.

Podemos então, por meio destas ponderações prévias, compreender melhor a resposta à pergunta, se a época kantiana é ou não esclarecida. O filósofo argumenta de maneira negativa, porém esperançosa, ao afirmar que sua época não é esclarecida, mas se encontra em esclarecimento (Aufklärung), mostrando, assim, somente indícios da passagem à maioridade. Ora, como o processo do esclarecimento (Aufklärung) não 
se esgota em uma simples época, seria de todo errôneo asseverar que uma época é esclarecida, como se estivesse cumprido todas as expectativas da Aufklärung. Ao caracterizarmos a noção de esclarecimento (Aufklärung) para Kant, é necessário pontuar que ela ultrapassa qualquer ideia fixa presente em uma determinada época ou revolução, sendo imprescindível enfatizar a noção de movimento proposta pelo filósofo a respeito da Aufklärung. Isso traz luz acerca da totalidade argumentativa da saída da menoridade, uma vez que o termo alemão representa uma ação que não se encerra nela, pelo contrário, se confunde com a própria existência do sujeito, sendo este movimento uma contínua tarefa para a humanidade. Tal tarefa se insere no decorrer da história do indivíduo sem se esgotar nele, na medida em que é a história do esclarecimento (Aufklärung) que possibilita a melhor compreensão da história do indivíduo.

É necessário também destacar que os ideais da Aufklärung compactuam com grande parte das exigências da Revolução Francesa, porém não se esgotam nela. Dessa maneira, poderíamos compreender a Revolução Francesa como mais um dos indícios do processo do esclarecimento (Aufklärung), mas não como o processo encarnado. Por mais que a Revolução Francesa ultrapasse as datas de seu acontecimento, ela se encerra em um momento específico, já a Aufklärung é uma passagem que se situa em diferentes épocas e culturas, sem um final com datas cronológicas. Nesse sentido, Kant narra em seu ensaio um pensamento e um fato que se conformam com esta ideia, ou seja, dispõe filosoficamente sua caracterização de Aufklärung, ao mesmo tempo que, historicamente, vê no reinado de Frederico II e também na Revolução Francesa signos de que o processo esclarecedor ocorre conforme a liberdade do uso público da razão for disposto aos homens.

Sob a perspectiva da história, podemos observar que Kant exalta a ideia segundo a qual a humanidade encontra-se em constante aperfeiçoamento. Em decorrência disso, ao observarmos a história da humanidade, veremos que é a história de seu progresso, o qual se vincula a uma ideia que serve de pressuposto para compreender este contínuo desenvolvimento. Visando alcançar um objetivo, galgam-se os passos necessários para isso e, portanto, supera-se a presente perspectiva e faz dela um outro objetivo, melhorando-o assim progressivamente, mesmo se este fim não for alcançado. A filosofia da história kantiana, marcada pela ideia de progresso presente no gênero humano, presta-nos auxílio para a compreensão da Aufklürung, porque desenvolve, assim como no ensaio que presentemente analisamos, a narrativa de uma transformação racional na história da humanidade.

Um ponto que também devemos destacar é que o elogio à liberdade do uso público da razão, presente no ensaio kantiano, faz-se por meio deste próprio instrumento, já que Kant publica um ensaio para que possa proporcionar uma contribuição filosófica ao meio erudito a respeito do tema em questão, mostrando assim que o uso público da razão é imprescindível inclusive para a declaração de sua importância. Podemos concluir então que, para Kant, a impossibilidade da caracterização de sua época como esclarecida resulta da própria composição do esclarecimento (Aufklärung), pois ele é um processo contínuo e inacabado. Consequentemente, uma afirmativa acerca de uma época já esclarecida é um contrassenso, uma vez que reconfigura a totalidade conceitual, trazendo-a para o âmbito do estático e alcançado. O esclarecimento (Aufklärung), segundo Kant, percorre épocas e culturas em meio ao desenvolvimento da humanidade, sem se exaurir em algum momento, já que a humanidade é passível de um inesgotável aprimoramento. O papel desempenhado pelo uso público da razão é, desta forma, imprescindível para que a saída da menoridade ocorra, já que todo o discurso que se submeta a uma exterioridade reflexiva não pode conformar-se com a disposição racional e autônoma presente no gênero humano, sendo ela a mais inofensiva das 
liberdades e, no entanto, a mais eficaz de todas segundo Kant, visto que se ela for proporcionada ao gênero humano, o processo de esclarecimento (Aufklärung) não é simplesmente possível, mas inevitável.

Correspondência: Wagner Barbosa de Barros. Universidade Federal de São Carlos - UFSCar, Rodovia Washington Luís, Km 235, CEP 13560 905, São Carlos, SP, Brasil. E-mail: wagnerbarros71@gmail.com Conflito de interesses: Nenhum

Todos os autores leram e aprovam a versão final submetida a revista Em curso. 


\section{Bibliografia}

KANT, Immanuel. Resposta à pergunta: que é “Esclarecimento" (Aufklärung)? In: Textos seletos.

Trad. de Floriano de Souza Fernandes. $7^{\mathrm{a}}$ ed. Petrópolis: Vozes, 2011.

. Ideia de uma história universal de um ponto de vista cosmopolita. Trad. de Rodrigo Naves e Ricardo R. Terra. $2^{a}$ ed. São Paulo: Martins Fontes, 2004.

BICCA, Luiz. Racionalidade Moderna e subjetividade. São Paulo: Loyola, 1997.

CASSIRER, Ernst. Kant, vida y doctrina. Trad. de Wenceslao Roces. México: Fondo de Cultura Econômica, 1948.

HERRERO, Francisco. J. Religião e história em Kant. Trad. de José A. Ceschin. São Paulo: Loyola, 1991.

MAYOS, Gonçal. "O Iluminismo frente ao romantismo no marco da subjetividade moderna". In: Ilustración y Romantismo. Introducción a la polémica entre Kant y Herder. Trad. de Karine Salgado. Barcelona: Herder, 2004.

MENEZES, Edmilson. História e esperança em Kant. São Cristóvão, SE: Editora UFS, Fundação Oviêdo Teixeira, 2000.

“Kant e a ideia de educação das Luzes”. Revista Educação e Filosofia, vol. 14, n 26/27, jan./jun. e jul./dez. (2000), pp. 113-26.

WOOD, Allen W. Kant. Trad. de Delamar José Volpato Dutra. Porto Alegre: Artmed, 2008. 